\title{
O contexto brasileiro da fotografia com temática científica
}

\section{André Amaral Gonçalves Bianco}

Coordenador do Núcleo de Fotografia Científica, Universidade Federal de São Paulo (UNIFESP), São Paulo, Brasil

Correspondencia: andrequim@gmail.com

\section{INTRODUÇÃO}

Antes de expor meus pensamentos sobre a fotografia científica, preciso definir sob quais aspectos científicos envolverei você, leitor, nas próximas páginas desse "ponto de vista". Em minha opinião, embasada pela formação adquirida tanto em Fotografia, quanto em Filosofia da Ciência, a Fotografia per si já se constitui em um ramo do conhecimento humano, portanto, um ramo da Ciência. Ela é formada por técnicas em graus de sofisticações e diversidades comparáveis a outras tecnologias que nos obrigam a um processo contínuo de estudo e atualização. Para exemplificar, basta pensarmos nas mudanças no modo de produção de imagens, desde as câmeras fotográficas lambe-lambe às câmeras disponíveis nos smartphones. Portanto, em minha opinião, a fotografia sempre esteve e sempre estará atrelada ao desenvolvimento da Ciência e o objetivo desse artigo é apresentar minhas considerações acerca de uma nova área que vem tomando força no Brasil, e que no exterior já possui uma dinâmica intensa, à qual tratarei por Fotografia com Temática Científica (FTC).

A Fotografia pode ser subdividida em diversos segmentos, tais como: publicidade, moda, gastronomia, newborn (que se ocupa em realizar registros de recém-nascidos), casamento, landscape (fotografia de paisagens), nu, arquitetura, natureza, dentre outros. O que define cada um desses segmentos são os temas 
registrados pelos fotógrafos e não as técnicas utilizadas por eles; até porque muitas das técnicas são comuns aos diferentes segmentos da fotografia. Sendo assim, por extensão, o que definirá a FTC são os temas vinculados ao universo científico.

Portanto, para definir a FTC, será necessário antecipar uma definição de ciência, mesmo que breve e despretensiosa, apenas para embasar esse ponto de vista, sem a intensão de esgotar o assunto.

\section{CIÊNCIA}

Chalmers (1993) apresentou a concepção de ciência por meio das correntes indutivista, falsificacionista, racionalista, relativista, individualista, objetivista, instrumentalista e realista. De acordo com o autor, não há uma categoria geral para a ciência e nenhum conceito à altura da tarefa de caracterizar a ciência como a busca pela verdade.

Posteriormente, Chalmers (1994) estabeleceu como metas da ciência a transformação, o aperfeiçoamento e a ampliação do nosso conhecimento. Esses objetivos devem ser alcançados por meio de testes severos, com condições controladas e variáveis isoladas.

Em Fourez (1995), foram definidas três noções comumente utilizadas de ciência: pura, aplicada e tecnologias. Para o autor, não há preocupação em aplicar os resultados das ciências puras em um contexto societário, de modo que os seus praticantes se concentram na aquisição de novos conhecimentos. Já a realização das ciências aplicadas visa destinar seus resultados diretamente à sociedade. Por fim, o autor fala em tecnologias quando quer tratar de aplicações concretas e operacionais em um dado contexto social. Portanto, podemos entender que a FTC objetiva realizar a reprodução imagética de atividades humanas com a finalidade de transformação, aperfeiçoamento e ampliação do nosso conhecimento, seja de caráter puro, aplicado ou tecnológico.

\section{UM RETRATO DA FTC NO BRASIL}

Com o objetivo de retratar o atual contexto da FTC no Brasil, foi realizada uma busca por artigos científicos nas bases 
de dados Pubmed Brasil, Scielo e Google Acadêmico, com o descritor fotografia científica. A pesquisa revelou que a Fotografia é utilizada em praticamente todas as áreas do conhecimento. Abaixo, apresento um recorte dos trabalhos encontrados, que demonstra a aplicação da fotografia no universo científico:

Silva (2014) realizou um estudo sobre o uso da fotografia na medicina ocidental, da segunda metade do século XIX às primeiras décadas do século XX, e concluiu que, nesse período, a fotografia sedimentou o seu papel como instrumento de registro, de conhecimento e de divulgação das práticas médicas.

Clode (2010) traçou um paralelo entre $o$ nascimento da fotografia $\mathrm{e} a$ evolução da Medicina. Para o autor, não há evento médico importante que não tenha sido registrado por meio da fotografia. Atualmente, a fotografia vem sendo utilizada em praticamente todas as especialidades da Medicina, como por exemplo, na comunicação e no ensino (Techy, 2006) e na documentação clínicocirúrgica da Cirurgia Plástica (Hochman et al., 2005); na prática clínica e na pesquisa
(Miot et al., 2006) e como veículo de informação do conhecimento (Vallarelli, 2011) em Dermatologia.

Yamamura e Souza apresentaram um relato do ensino da fotografia a alunos de pós-graduação do curso de Medicina Veterinária, da Universidade Estadual de Londrina. De acordo com os autores, a fotografia é utilizada nas aulas como elemento enriquecedor da aprendizagem e nas ilustrações e divulgações dos resultados de pesquisas em eventos e publicações científicas. Para eles, as imagens fotográficas asseveram a veracidade dos resultados da pesquisa e também servem como ilustrações do campo editorial veterinário; propiciando a professores e alunos do curso de Medicina Veterinária material visual e impresso de boa qualidade para o exercício do olhar, tornando-os mais humanistas e sensíveis.

Machado et al. (2005) concluíram por meio de sua pesquisa que a fotografia digital apresenta padrões de qualidade que permitem o seu uso na Ortodontia, alçando a fotografia ao patamar de recurso 
adequado à obtenção de imagens para a

\section{Odontologia.}

A fotografia também é utilizada no auxílio do diagnóstico e no estudo do prognóstico de pacientes na área da Motricidade Oral, em Fonoaudiologia (Silveira et al., 2006).

Em Enfermagem, a fotografia é utilizada para auxiliar profissionais na observação, evolução e registro claro e preciso das lesões e tecidos adjacentes (Faria e Peres, 2009). Uma revisão bibliográfica realizada na área por Galvão et al. (2013) encontrou sete artigos em inglês, português ou espanhol, nos quais a fotografia foi utilizada no cuidado com pacientes com doença mental, na evolução de feridas e como forma de aprimorar a comunicação entre equipe de saúde e clientes.

A fotografia tem utilidade em inquéritos alimentares da Nutrição. Em uma revisão bibliográfica foram analisados 21 artigos em português e inglês, com as palavras-chaves: "foto/fotografia" ou "filmagem" conjugadas a "digital", "alimento", “tamanho da porção", “refeição" e/ou "ingestão alimentar", bem como a associação desses termos com: “precisão", “validade” e "validação". Pelos resultados da pesquisa, é possível afirmar que o método fotográfico pode ser aplicado para registro das porções de referência, servidas e rejeitadas (Rodrigues e Proença, 2011).

A fotografia também é utilizada na pesquisa em Antropologia (Attané e Langewiesche, 2005), como instrumento de pesquisa e como "ilustração interpretativa" de apresentação dos resultados de uma pesquisa.

Albuquerque e Klein entendem a fotografia como fonte histórica e como tal, propõe encara-la como documento, rico em informações e significados, que nos coloca direto com um momento, um personagem e uma época.

A forma como a fotografia tem sido trabalhada na pesquisa em Sociologia foi investigada por Caetano (2008). A autora afirma que a fotografia assume importância fundamental na compreensão da organização das existências contemporâneas.

A fotografia vem sendo amplamente utilizada na pesquisa em Psicologia, para 
investigação das mais diversas questões. Neiva-Silva e Koller (2002) realizaram um levantamento histórico-metodológico do uso da fotografia na ciência psicológica e identificaram quatro funções principais da fotografia nos diferentes métodos adotados: registro, modelo, feedback e autofotografia.

O trabalho de Machado-Júnior (2015) apresentou a contribuição da fotografia para a problematização dos estudos em Pedagogia e o autor sugeriu que ela pode oferecer caminhos teóricos e metodológicos a partir de bibliografia produzida no campo das ciências humanas e da análise do discurso.

Para Travassos (2001), a importância da fotografia para a Geografia encontra-se na possibilidade de nos indicar maneiras pelas quais podemos olhar a paisagem e levar o aluno a desbravar o mundo além da sala de aula, estruturando e organizando sua interface com o real e o mundo.

$\mathrm{Na}$ Oceanografia, a fotografia foi utilizada para registrar grandes feitos, descobertas e expedições (Jardim et al., 2014). Com a evolução tecnológica dos equipamentos a fotografia criou novas possibilidades de registros, ao ponto de ter sido utilizada por Kitahara (2007) para a identificação de zooplâncton marinho.

O aspecto educativo da fotografia para a Biologia foi retratado no trabalho de Bruzzo (2013), no qual a autora realizou um relato do potencial da fotografia para o aprofundamento da discussão das condições de vida de animais selvagens confinados em zoológicos.

\section{EQUIPAMENTOS UTILIZADOS NA} FTC

A FTC utiliza equipamentos do mercado fotográfico e complementarmente equipamentos ópticos empregados em pesquisas científicas. Como já mencionei, não acredito que o instrumental seja critério para definir o tema de um segmento fotográfico. Como fotógrafo interessado em temas relacionados à ciência, muitas vezes utilizei técnicas comuns à fotografia de gastronomia para obter resultados desejados na apresentação de reações químicas, fiz uso da minha objetiva $50 \mathrm{~mm}$ (tornada memorável na retratação de pessoas pelo fotógrafo Henri 
Cartier-Bresson), para registrar animais e produzir conteúdo imagético para materiais didáticos e aulas de Bioquímica.

Da mesma forma, nada impede que um fotógrafo de outro segmento utilize equipamentos comuns ao universo da FTC para obter o resultado desejado em suas imagens - e isso não irá fazer das suas imagens, fotografias científicas, pois o tema e a finalidade delas são outras.

Entretanto, é fato que determinadas técnicas são frequentes entre os fotógrafos que registram temas ligados à ciência, devido a peculiaridades dos motivos fotografados por esses profissionais. Assim, são técnicas comuns à FTC a microscopia eletrônica, fotomicrografia, microscopia óptica, imunofluorescência, macro e microfotografia, fotografias com o uso de objetivas grande angulares, normal e teleobjetivas (no último caso, destacam-se os equipamentos ópticos para registros astronômicos).

\section{O MERCADO DE TRABALHO}

\section{BRASILEIRO PARA A FTC}

Enquanto mercado de trabalho, a FTC é um fenômeno recente no Brasil e encontra espaço em jornais e revistas de divulgação científica, sobretudo a partir da década de 1990, quando as ações de divulgação científica se tornaram mais intensas na expansão das publicações de seções de jornais voltadas para a divulgação da ciência (Pimenta e Gouvêa, 2009). Apesar da maioria dos temas ser relacionado à Biologia e à Saúde, há demanda por imagens com temas de outras Ciências da Natureza (Física e Química) e afins (como a Geografia e a Geologia).

Os livros didáticos também representam um importante nicho de mercado para o fotógrafo com temática científica. É comum as editoras não produzirem material imagético próprio e o adquirirem de bancos de imagens.

Há ainda uma pequena parcela de trabalhos de pesquisadores divulgados em revistas científicas em apresentações de reuniões acadêmicas - pequena porque é uma característica dos trabalhos acadêmicos a produção imagética ser 
realizada pelos próprios pesquisadores que contém imagens produzidas por fotógrafos profissionais. Entretanto, nos EUA já existem empresas que prestam serviços especializados para esse público.

\section{A FORMAÇÃO DO FOTÓGRAFO DE}

\section{CIÊNCIA}

Para finalizar, vale ressaltar que já há iniciativas para a formação específica de profissionais da fotografia interessados na temática científica; seja para atuarem em seus projetos pessoais, seja para atenderem o mercado.

A fotógrafa de ciência Felice Frankel é pesquisadora no Centro de Ciência e Engenharia de Materiais do Instituto de Tecnologia de Massachusetts (MIT) e autora de livros como Envisioning Science (2002), No Small Matter (2009) e On The Surface Of Things (2009). Em sua obra Envivioning Science, Frankel apresentou vários elementos fundamentais ao desenvolvimento da autonomia para a produção de imagens com temática científica. A autora enfatiza a importância de pesquisadores se habilitarem em técnicas fotográficas e aprimorarem sua produção imagética de artigos científicos, palestras e pôsteres. Em suas palavras, "uma imagem comunica seu trabalho mais efetivamente para colegas e público em geral".

No campus Diadema, da Universidade Federal de São Paulo (UNIFESP), coordeno desde 2014 o Núcleo de Fotografia Científica - polo de pesquisa e extensão universitária que tem entre as suas atividades a oferta de cursos de fotografia científica nos níveis básico, intermediário e avançado. Por meio desses cursos, nos esforçamos para disponibilizar uma formação em fotografia científica aos estudantes dos diversos cursos da UNIFESP. 


\section{REFERÊNCIAS}

Albuquerque MBM, Klein LE. 1987. Pensando a fotografia como fonte histórica. Cadernos de Saúde Pública. 3(3): 297-305.

Attané A, Langewiesche K. 2005. Reflexões metodológicas sobre os usos da fotografia na antropologia. Cadernos de Antropologia e Imagem. 21(2): 133-151.

Bruzzo C. 2013. O papel educativo da fotografia de vida selvagem. Educação \& Sociedade. 34(122): 287-305.

Caetano A. 2008. Sociologia e fotografia. Retrato sociológico do estado da relação em Portugal. CIES e-Working paper. Lisboa.

Chalmers AF. 1993. O que é ciência afinal? $1^{\text {a }}$ ed. Brasília (BR): Editora Brasiliense. 230 p.

Chalmers AF. 1994. A fabricação da Ciência. São Paulo (SP): Editora da UNESP. 185 p.

Clode JJPE. 2010. História da Fotografia e da sua aplicação à Medicina. Cadernos de Otorrinolaringologia. Clínica, Investigação e Inovação. p. 1-23.

Faria NGF, Peres HHC. 2009. Análise da produção científica sobre documentações fotográficas de feridas em enfermagem. Revista Eletrônica de Enfermagem 11(3): 704-11.

Fourez G. 1995. A construção das ciências: introdução à Filosofia e à Ética das Ciências. São Paulo (SP): Editora da UNESP. 321 p.

Frankel F. Envisioning Science. 2002. Cambridge (MA): The MIT Press. 336 p.

Frankel F, Whitesides GM. 2009. No Small Matter. Cambridge (MA): Harvard University Press. 192 p.

Frankel F, Whitesides GM. 2009. On the Surface of Things: Images of the Extraordinary in Science. Cambridge (MA): Harvard University Press. 160 p.
Galvão MTG, Alexandre HO, Dantas PB, Lima ICV, Lopes EM. 2013. Uso da fotografia no processo do cuidar: tendências das ações de enfermagem. Ciencia y Enfermeria. 19(3): 3139.

Hochman B, Nahas FX, Ferreira LM. 2005. Fotografia aplicada na pesquisa clínicocirúrgica. Acta Cirúrgica Brasileira. 20(2): 1925.

Jardim ME, Peres IM, Ré PB, Costa FM. 2014. A prática oceanográfica e a coleção iconográfica do rei dom Carlos I. História, Ciências, Saúde Manguinhos. 201(23): 883-909.

Kitahara EM. 2007. O uso da fotografia e da imagem digital em pesquisas oceanográfica: novos rumos proporcionados pela evolução do processo digital. Conexão - Comunicação e Cultura. 6(12): 125-137.

Machado AW, Oliveira DD, Leite EB, Lana AMQ. 2005. Fotografia digital $x$ analógica: a diferença na qualidade é perceptível? Revista Dental Press de Ortodontia e Ortopedia Facial. 10(4): 115123.

Machado-Júnior CS. 2015. Fotografia, imprensa de variedades e educação: discursos visuais e textuais sob o foco de uma pedagogia de revista. História da Educação. 19(47): 109-128.

Miot HA, Paixão MP, Paschoal FM. 2006. Fundamentos da fotografia digital em Dermatologia. Anais Brasileiros de Dermatologia. 81(2): 174-80.

Pimenta M, Gouvêa G. 2009. Imagens na divulgação científica em jornais de grande circulação no Brasil. Atas do VII Encontro Nacional de Pesquisa em Educação em Ciências, Florianópolis, Brasil: ABRAPEC. p 1-15.

Rodrigues AGM, Proença RPC. 2011. Uso de imagens de alimentos na avaliação do consumo alimentar. Revista de Nutrição. 24(5): 765-776.

Silva JR. 2014. Fotografia e ciência: a utopia da imagem objetiva e seus usos nas ciências e na 
PONTO DE VISTA: O contexto brasileiro da fotografia com temática científica

medicina. Boletim do Museu Paraense Emílio

Goeldi - Ciências Humanas. 9(2): 343-360.

Silveira MC, Sígolo C, Quintal M, Sakano E, Tessitore A. 2006. Proposta de documentação fotográfica em motricidade oral. Revista CEFAC. 8(4): 485-92.

Techy A. A importância da fotografia na medicina. Revista Brasileira de Reumatologia. 46(3): 207209.

Travassos LEP. 2001. A fotografia como instrumento de auxílio no ensino da Geografia. Revista de Biologia e Ciências da Terra. 1(2): 13.

Vallarelli AFA. 2011. Critérios para submissão de fotografias. Anais Brasileiros de Dermatologia. 86(2): 212-214.

Yamamura MH, Souza MIPO. 2009. O ensino de fotografia no curso de Medicina Veterinária. Semina: Ciências Agrárias. 30(2): 461-469. 